\title{
Analytical Hierarchical Process (AHP) for the Selection of Conveyance in a Company that Distributes Cement Blocks at a Municipal Level
}

\author{
Leonardo D. Bula ${ }^{1}$, Cesar Vergara Rodriguez ${ }^{1}$ and Boris Medina ${ }^{2}$ \\ 'Corporación Universitaria del Caribe, Facultad de Ciencias Básicas, Ingeniería y Arquitectura, Sincelejo, Colombia; \\ leonardo.bula@cecar.edu.co, \\ cesar.vergara@cecar.edu.co \\ 2Universidad de Sucre, Facultad de Ingeniería, Sincelejo, Colombia; boris.medina@unisucre.edu.co
}

\begin{abstract}
Objectives: This article shows the application of the Analytical Hierarchical Process to select conveyance in a company that distributes Cement Blocks. Methodology: The Analytical Hierarchical Process was applied taking into account the criteria, Variable Cost, Service, Capacity and Reliability, and conveyance that fit the characteristics of the municipality and the company. Findings: The Process, which allowed to evaluate these criteria and based on these determine the prioritization of the alternatives and the selection of the most efficient method according to the selected criteria. Application / Improvements: The Analytical Hierarchical Process (AHP) is a tool which allows supporting Decision Making, by analysing multiple criteria and depending on their relationship, obtaining a hierarchy in the alternatives, being the one with the greatest impact or hierarchy the decision to choose.
\end{abstract}

Keywords: Alternatives, Analytical Hierarchical Analysis Process, Criteria, Hierarchy, Transportation MeansAHP

\section{Introduction}

Decision making is a fundamental part of the business world; in an increasingly competitive world, where strategic and tactical decisions in an organization can define its survival and positioning in a global market like today. When we face a process of decision making or alternatives selection, we must bear in mind that this decision is subject to various criteria or objectives; a feature that increases the complexity of the selection processes, generating tools that manage to involve each and every one of the evaluated criteria allowing selecting that alternative with the greatest impact on the organization.

The Analytical Hierarchical Process (AHP) is a tool, which allows decision making to be supported, by analysing multiple criteria and depending on their relationship, obtaining a hierarchy in the alternatives, with the decision having the highest impact or hierarchy to choose. This tool, due to its simplicity and clarity, allows it to be chosen as a methodology for decision making in small and medium-sized companies, thus achieving better strategic and tactical decisions. The present article describes the methodology used for the decision making of a conveyance for a concrete blockdistribution company at the municipal level, based on the Hierarchical Analysis Process, for its development an application was created in Excel allowing to automate the calculations and standardize the decision making process.

\section{Materials and Methods}

\subsection{The Hierarchical Analysis Process (AHP)}

AHP uses the principle of hierarchical composition, originating priorities in the criteria, and from these, obtain priorities that will allow choosing the alternatives of better weighting or ranking ${ }^{1}$ In $^{2}$ AHP deals directly with ordered importance pairs of priorities, preference or

${ }^{*}$ Author for correspondence 
probability of elements pairs based on a common attribute or criterion represented in the decision hierarchy. We believe that this is the natural (but refined) method that people followed in making decisions long before utility functions were developed and before the AHP was formally developed. AHP makes it possible to make group decisions by adding opinions, in such a way that it satisfies the reciprocal relationship when comparing two elements. Then take the geometric opinions average. When the group consists of experts, each one elaborates its own hierarchy, and the AHP combines the results with the geometric average.

\subsection{Methodological Scheme of the AHP}

One of the most relevant parts of the AHP is the structuring of the hierarchy of the problem, a stage in which the problem is broken down into its relevant components. The AHP elementary hierarchy is made up of: the identification of the problem, the establishment of the objective or goal, the identification of the criteria and the alternatives $^{3-6}$, as shown in Figure 1.

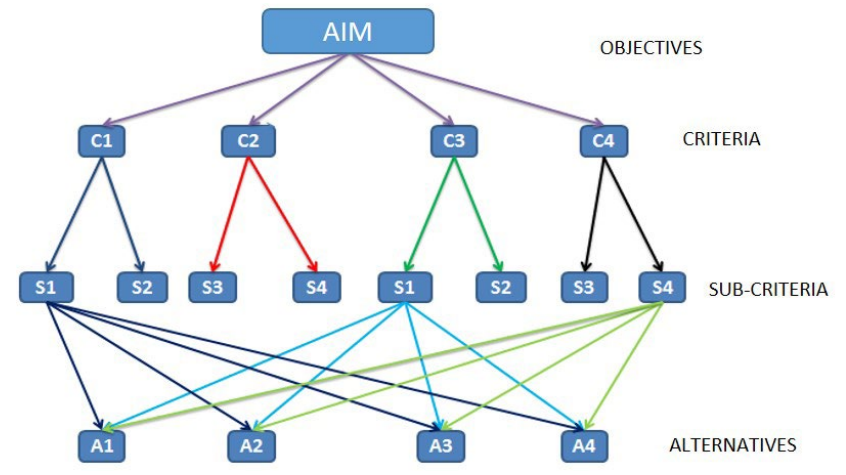

Figure 1. Hierarchical model for decision making.

\subsubsection{Problem Identification}

It is the situation that you want to solve by selecting one of the available alternatives or the prioritization (ranking) of them.

\subsubsection{Objective Definition}

A goal is an identified address to improve an existing situation. The objective is at an independent level and the other elements of the hierarchy that will be the sub-objectives or criteria, sub-criteria and alternatives point to the achievement of the same.

\subsubsection{Criteria Identification}

These are the relevant dimensions that significantly affect the objectives and must express the preferences of those involved in the decision making process.

\subsubsection{Alternatives Identification}

They correspond to feasible proposals through which the general objective can be achieved. Each of the alternatives presents features with pros and cons.

Once the elementary hierarchy process has been carried out, the model is evaluated, within which a set of matrices comparison is constructed in pairs, where each higher level element (Criteria) is compared with the lower level elements (Alternatives), that means, the alternatives are compared with each other, taking into account the criteria ${ }^{7,8}$; this process allows the establishment of the Relative Priorities. Once the comparison is made, we continue with the evaluation of the Hierarchical Model, whose evaluation is followed as ${ }^{5,9}$.

a. Establish Priorities: By making the aforementioned comparison, the relative importance of the established Hierarchical Model parts is determined.

b. Issuing Judgments and Evaluations: Judgments are the basis of the process carried out by AHP. These Trials must be guided by scientific and technical information and the evaluator's expertise.

Table 1 presents the Saaty scale $e^{5,10}$ that allows measuring the judgments issued by the evaluators. The emission of judgments consists in comparing in pairs the elements of each level (previously defined), where each element belonging to a level has a hierarchy. This comparison is made between the different levels contemplated in Figure 1 and the influence that exists between its elements (Upper Level - Lower Level). Once all comparisons have been made, the final result issued by the evaluator is obtained; that means, a priority ordering of alternatives is made, which arises from components comparisons of the hierarchical model, carried out by the evaluator. 
Table 1. Scale of saaty creator of the AHP

\begin{tabular}{|l|l|l|}
\hline Numerical Scale & Verbal Scale & Explanation \\
\hline 1.0 & Both elements are of equal importance. & $\begin{array}{l}\text { Both elements contribute to the property in the same } \\
\text { way. }\end{array}$ \\
\hline 3.0 & Moderate importance of one element over another & $\begin{array}{l}\text { Experience and judgment favour one element over } \\
\text { another. }\end{array}$ \\
\hline 5.0 & Strong importance of one element over another. & One element is strongly favoured. \\
\hline 7.0 & Very strong importance of one element over another. & One element is very strongly dominant. \\
\hline 9.0 & Extreme importance of one element over another. & $\begin{array}{l}\text { An element is favoured, at least with an order of } \\
\text { magnitude of difference. }\end{array}$ \\
\hline $2.0,4.0,6.0,8.0$ & Intermediate values between two adjacent judgments. & Used as consensus values between two judgments. \\
\hline 0.1 increments & $\begin{array}{l}\text { Intermediate values in the finest graduation of } 0.1 \\
\text { (For example 5.2 is a valid entry). }\end{array}$ & \begin{tabular}{l} 
Used for finer judgments graduations. \\
\hline
\end{tabular}
\end{tabular}

\section{Results}

For the development of the proposal we used the Hierarchical Analysis Process established by Saaty ${ }^{11}$, designed to solve complex multiple criteria problems. Method that consists in the realization of paired comparisons of previously established criteria being these, the dimensions that significantly affect the objectives, where the preferences of those involved in the decision making are indicated ${ }^{12,13,14}$, these criteria must be Include quantitative and qualitative aspects.

For the application of the Hierarchical Analysis method, a comparison matrix of paired criteria was designed, allowing comparing each one of the criteria with the others; subsequently, the assessment of importance relative of the criteria was carried out, and based on these assessments, a ranking of alternatives was established according to the assessments made.

The concrete block Production Company seeks to select a transport method for its product; for this, four selection criteria and four alternatives shown in Figure 2 were defined.

The selected criteria were defined as follows:

- Variable Cost (U / kg): The variable cost was associated to the unit by weight (given in kilograms), referring to the variable costs associated with the transportation of each unit, taking into account the average route, the fuel consumption, the equipment and labour depreciation.

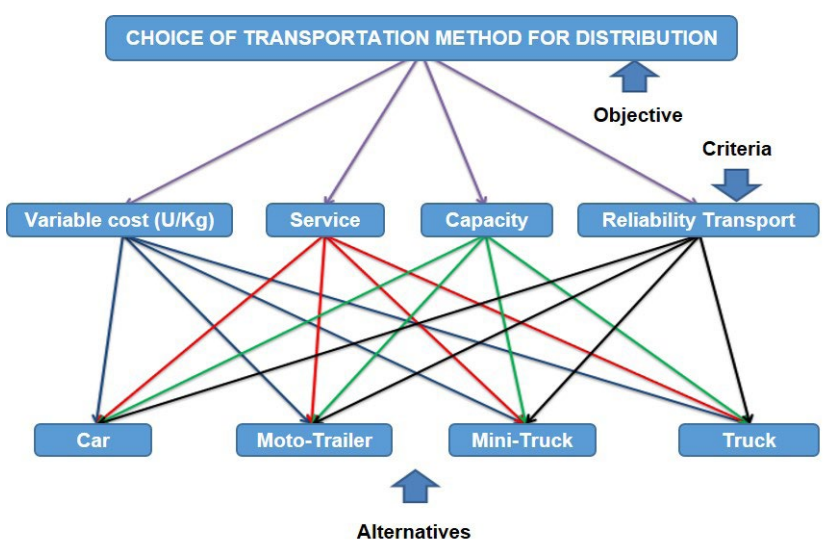

Figure 2. Selection hierarchy of a transport method.

- Service: The service was defined as the ability to respond in the shortest time possible to market demands.

- Capacity: The capacity refers to the number of units (Weight) that can be transported by each conveyance evaluated.

- Reliability: The Reliability of transport considered the market road infrastructure to which the product is directed and the maintenance associated with the failure rate of the equipment that is subjected to long working hours.

From criteria and alternatives definition, applying the Saaty methodology, comparison matrices were calculated by criteria taking into account Table 1 , and whose results are detailed in Table 2. 
Table 2. Criteria and alternatives for conveyance selection of concrete blocks

\begin{tabular}{|l|c|c|c|c|}
\hline Criteria Alternatives & variable Cost U/km & Fast Service & Capacity & Transportation Reliability \\
\hline Car & $\$ 80,35$ & 30 & 50 & 50 \\
\hline Moto Trailer & $\$ 118,68$ & 50 & 80 & 80 \\
\hline Mini truck & $\$ 453,72$ & 80 & 200 & 100 \\
\hline Truck & $\$ 413,98$ & 70 & 100 & 100 \\
\hline
\end{tabular}

Once the criteria have been defined, a peer analysis is carried out, comparing each one of the alternatives with each one of the criteria in a wide range. As shown in Table 3, the Variable Cost criterion (Cost Variable U / $\mathrm{Km}$ ) is evaluated with conveyance respect, in which a value of 2 indicates that between Car and Motor-Trailer conveyance exists a relationship between equal and moderate; likewise, the value 7 indicates that the MotoTrailer is very strongly preferred than Truck. The values $1 / 2,1 / 4,1 / 3$ and $1 / 7$ correspond to the inverses, showing that the comparison is made in both directions; this explains why in the diagonal it is valued with 1 ; this evaluation is due to the factor comparison against it. This procedure is applied in each criterion with the results shown in Tables 4-6.

From evaluation matrices by criterion, the reference matrix of the criteria emerges, shown in Table 7, where all the matrices of the assessed criteria are unified.

Table 3. Evaluation matrix criterion 1

\begin{tabular}{|l|l|l|l|l|}
\hline CRITERIA 1: & \multicolumn{4}{l}{ Variable Cost U/km } \\
\hline & Car & Moto Trailer & Mini Truck & Truck \\
\hline Car & 1 & 2 & 4 & 4 \\
\hline Moto-Trailer & $1 / 2$ & 1 & 3 & 7 \\
\hline Mini-Truck & $1 / 4$ & $1 / 3$ & 1 & 2 \\
\hline Truck & $1 / 4$ & $1 / 7$ & $1 / 2$ & 1 \\
\hline
\end{tabular}

Table 4. Evaluation matrix criterion 2

\begin{tabular}{|l|l|l|l|l|}
\hline CRITERIA 2: & \multicolumn{4}{l}{ Fast Service } \\
\hline & Car & Moto Trailer & Mini Truck & Truck \\
\hline Car & 1 & $1 / 5$ & $1 / 3$ & 2 \\
\hline Moto Trailer & 5 & 1 & 4 & 6 \\
\hline Mini Truck & 3 & $1 / 4$ & 1 & 3 \\
\hline Truck & $1 / 2$ & $1 / 6$ & $1 / 3$ & 1 \\
\hline
\end{tabular}

Table 5. Evaluation matrix criterion 3

\begin{tabular}{|l|l|l|l|l|}
\hline CRITERIA 3 : & \multicolumn{4}{l}{ Capacity } \\
\hline & Car & Moto Trailer & Mini Truck & Truck \\
\hline Car & 1 & $1 / 3$ & $1 / 7$ & $1 / 9$ \\
\hline Moto Trailer & 3 & 1 & $1 / 3$ & $1 / 6$ \\
\hline Mini Truck & 7 & 3 & 1 & $1 / 4$ \\
\hline Truck & 9 & 6 & 4 & 1 \\
\hline
\end{tabular}

Table 6. Evaluation matrix criterion 4

\begin{tabular}{|l|l|l|l|l|}
\hline CRITERIA 4 : & \multicolumn{4}{l}{ Transportation Reliability } \\
\hline & Car & Moto Trailer & Mini Truck & Truck \\
\hline Car & 1 & $1 / 6$ & $1 / 9$ & $1 / 9$ \\
\hline Moto Trailer & 6 & 1 & $1 / 2$ & $1 / 3$ \\
\hline Mini Truck & 9 & 2 & 1 & 1 \\
\hline Truck & 9 & 3 & 1 & 1 \\
\hline
\end{tabular}

Table 7. Criteria reference matrix

\begin{tabular}{|l|l|l|l|l|}
\hline & Variable Cost U/km & Fast Service & Capacity & Transportation Reliability \\
\hline Variable Cost U/km & 1 & 5 & 3 & 4 \\
\hline Fast Service & $1 / 5$ & 1 & 3 & 2 \\
\hline Capacity & $1 / 3$ & $1 / 3$ & 1 & $1 / 3$ \\
\hline Transportation Reliability & $1 / 4$ & $1 / 2$ & 3 & 1 \\
\hline
\end{tabular}


Once the evaluation matrices were constructed by criteria, each criterion was normalized by calculating the priority vector and the consistency quotient. For the aforementioned calculation, the procedure was as follows:

\subsection{Normalized Matrix Calculation by Criterion}

The normalized matrix calculation for each criteria, shown in Table 8, was developed by dividing each column number of the criteria evaluation matrix by the total sum of the same column. This procedure of normalization by criteria seeks to assign weights to each criterion; therefore, for each criteria the same procedure was performed.

\subsection{Priority Vector Calculation by Criteria}

It is the each row average of the normalized matrix; Table 8 shows the priority vector calculation of the priority of
Criterion 1. Following the same procedure, the calculation was performed for the remaining criteria.

\subsection{Consistency Calculation}

Consistency is determined through the consistency ratio (CR); according to Saaty, a CR below 0.1 is considered acceptable and for cases where it is higher, the assessment of the judgments issued must be reconsidered. To calculate the CR shown in Table 9, the quotient between the Consistency Index (CI) and the Random Index was performed. The Saaty proposal in Table 10 must be taken into account to calculate the Random Index. Once the normalized matrix by criteria was calculated, it was unified, following the same standardization criterion in order to find the priority vector of the criteria shown in Table 11, vector necessary to find the global prioritization of the alternatives.

Table 8. Normalized matrix criterion 1

\begin{tabular}{|l|c|c|c|c|l|c|c|}
\hline \multirow{2}{*}{ CRITERIA 1 } & \multicolumn{5}{l|}{ Variable Cost U/km } & \multicolumn{1}{l|}{} \\
\cline { 2 - 8 } & Car & Moto Trailer & Mini Truck & Truck & Priority Criteria Vector: & Variable Cost U/km & CI = 0,0482340 \\
\hline Car & $1 / 2$ & $42 / 73$ & $8 / 17$ & $2 / 7$ & Car & 0,457911 & RI =0,90 \\
\hline Moto-Trailer & $1 / 4$ & $21 / 73$ & $6 / 17$ & $1 / 2$ & Moto-Trailer & 0,347653 & 0,120349 \\
\hline Mini-Truck & $1 / 8$ & $7 / 73$ & $2 / 17$ & $1 / 7$ & Mini-Truck & 0,074087 & CR =0,0535933 \\
\hline Truck & $1 / 8$ & $3 / 73$ & $1 / 17$ & $1 / 14$ & Truck & & \\
\hline
\end{tabular}

Table 9. Consistency indexes by criteria

\begin{tabular}{|l|c|c|c|}
\hline Criteria & Consistency Index (CI) & Random Index (RI) & Consistency Ratio (CR) \\
\hline Variable Cost U/km & 0,0482340 & & 0,0535933 \\
\hline Fast Service & 0,0424855 & 0,90 & 0,0472061 \\
\hline Capacity & 0,0495020 & & 0,0550022 \\
\cline { 1 - 2 } Transportation Reliability & 0,0153198 & & 0,0170219 \\
\hline
\end{tabular}

Table 10. Random index value according to the Alternatives number

\begin{tabular}{|c|c|}
\hline \multicolumn{2}{|c|}{ Coefficient of consistency } \\
\hline Number of alternatives & Randomindex \\
\hline $\mathrm{m}$ & RI \\
\hline 3 & 0,58 \\
\hline 4 & 0,90 \\
\hline 5 & 1,12 \\
\hline 6 & 1,24 \\
\hline 7 & 1,32 \\
\hline 8 & 1,41 \\
\hline
\end{tabular}


Table 11. Unified criteria matrix

\begin{tabular}{|l|c|c|c|c|l|l|}
\hline & Variable Cost U/km & Fast Service & Capacity & Transportation Reliability & \multicolumn{2}{|c|}{ Criteria Priority Vector } \\
\hline Variable Cost U/km & $23 / 41$ & $30 / 41$ & $3 / 10$ & $6 / 11$ & Variable Cost U/km & 0,534477 \\
\hline Fast Service & $11 / 98$ & $6 / 41$ & $3 / 10$ & $3 / 11$ & Fast Service & 0,207805 \\
\hline Capacity & $17 / 91$ & $2 / 41$ & $1 / 10$ & $1 / 22$ & Capacity & 0,095288 \\
\hline $\begin{array}{l}\text { Transportation } \\
\text { Reliability }\end{array}$ & $8 / 57$ & $3 / 41$ & $3 / 10$ & $3 / 22$ & $\begin{array}{l}\text { Transportation } \\
\text { Reliability }\end{array}$ & 0,162430 \\
\hline
\end{tabular}

\begin{tabular}{|l|c|c|c|c|}
\hline Table 12. Priority matrix & \multicolumn{5}{l|}{ Capacity } & Transportation Reliability \\
\hline & Variable Cost U/km & Fast Service & 0,04527 & 0,03876 \\
\hline Car & 0,45791 & 0,11362 & 0,10418 & 0,18250 \\
\hline Moto Trailer & 0,34765 & 0,58769 & 0,24664 & 0,36910 \\
\hline Truck & 0,12035 & 0,22422 & 0,60391 & 0,40964 \\
\hline
\end{tabular}

When the previous step was carried out, the priority matrix shown in Table 12 was developed, taking into account the priority vectors calculated from the normalization matrices by criterion. From the priority vectors by criteria of Table 11 unified criteria matrix and the priority matrix, the alternative prioritization vector was found, detailed in Table 13, calculated by the product of the priority vectors by criteria and each row of the priority matrix.

Table 13. Alternatives prioritization vector

\begin{tabular}{|l|l|}
\hline \multicolumn{2}{|l|}{ Alternatives Prioritization Vector } \\
\hline Car & 0,278962 \\
\hline Moto Trailer & 0,347509 \\
\hline Mini Truck & 0,194373 \\
\hline Truck & 0,179156 \\
\hline
\end{tabular}

The alternative of greater hierarchy, according to Figure 3 is the Moto-Trailer represented by a value of $34.75 \%$, followed by the Car with $27.89 \%$; In this case, the conveyance to be implemented is the Moto-Trailer, taking into account the selection criteria evaluated.

\section{Conclusions}

The implementation of the Analytical Hierarchical Process (AHP) as a tool to support decision-making demonstrates the numerous advantages that this process entails, allowing the evaluation of several alternatives with different criteria and making the right decisions at any level; likewise, this process allows us to weigh each of the selected criteria, using qualitative and quantitative aspects in such a way that the assessment or judgment issued by the evaluators is consistent.

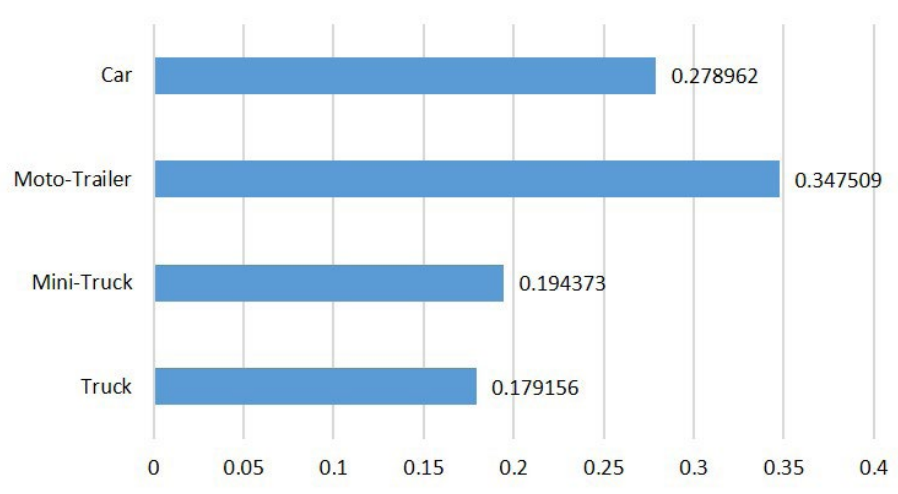

Figure 3. Hierarchy of alternatives. 
The application of the AHP allows to achieve an integration of judgments and to base an election in such a way that, although there are several evaluators, the same decision is reached. Its versatility, simplicity, clarity and mathematical consistency make this tool a strategic ally for the decision making of any Organization. It should be noted that this tool must be supported by scientific and technical knowledge and the evaluator expertise.

In the present article it is evident that taking into account the analysed criteria, alternatives were established allowing to select the Moto-Trailer alternative as a conveyance for a concrete block distribution company as the option of greater acceptance in the study according to the established criteria. Likewise, a template was established in Excel as a tool to support multicriteria decision making under the AHP Methodology, making decisions faster.

\section{References}

1. Saaty TL. Decision-making with the AHP: Why is the principal eigenvector necessary? European Journal of Operational Research. 2003; 145(1):85-91. crossref

2. Martínez E, Escudey M. Evaluación y decisión multicriterio: Reflexiones y experiencias. Santiago: UNESCO; 1997.

3. Herrera MF, Osorio JC. Modelo para la gestión de proveedores utilizando AHP fuzzy. Estudios Gerenciales. 2006; 99(1):69-88.

4. Martínez E. Aplicación del proceso jerárquico de análisis en la selección de la localización de una PYME. Anuario jurídico y económico escurialense. 2007; 11:523-42.

5. Ranjit RG, Rushina S, Sanjeev B. Online Store Selection Attributes and Patronage Intentions: An Empirical Analysis of the Indian E-Retailing Industry. Indian Journal of Science and Technology. 2016; 9(44):1-14.
6. Mahmood E, Mohammad A, Ramtin N, Saeed A. Prioritizing PMO Functions in Organizations: A Group Fuzzy Decision Making Approach. Indian Journal of Science and Technology. 2016; 9(13):1-9.

7. Saaty TL. Decision making with the analytic hierarchy process. International Journal of Services Sciences. 2008; 1(1):1-16. crossref

8. Saaty TL. How to make a decision: the analytic hierarchy process. Interfaces. 1994; 24(6):19-43. crossref

9. Mogollón R. El AHP (Proceso Analítico Jerárquico) y su aplicación para determinar los usos de las tierras: El caso de Brasil. Proyecto regional "Información sobre tierras y aguas para un desarrollo Agrícola sostenible" (proyecto gcp/rla/126/jpn). 2000; p.1-78.

10. Saaty TL. Rank from comparisons and from ratings in the analytic hierarchy/network processes. European Journal of Operational Research. 2006; 168(2):557-70. crossref

11. Ramírez ML. Método de jerarquías analíticas de Saaty en la ponderación de variables: Aplicación al nivel de mortalidad y morbilidad en la provincia del chaco. Comunicaciones Científicas y Tecnológicas, Universidad Nacional del Nordeste. 2004; p.1-4.

12. Hurtado T, Bruno G. El Proceso de análisis jerárquico (AHP) como herramienta para la toma de decisiones en la selección de proveedores: aplicación en la selección del proveedor para la Empresa Gráfica Comercial MYE S.R.L. Lima: Universidad Nacional Mayor de San Marcos. Facultad de Ciencias Matemáticas. 2005; p.74-5.

13. Osorio JC, Orejuela JP. El proceso de análisis jerárquico (AHP) y la toma de decisiones multicriterio: Ejemplo de aplicación. Scientia et Technica. 2008; 14(39):1-7.

14. Soma P. Multivariate Bank Performance Analysis using Standardized CAMEL Methodology and Fuzzy Analytical Hierarchical Process. Indian Journal of Science and Technology. 2017; 10(23):1-17. 